\title{
DMT self-administration by monkeys in isolation
}

\author{
RONALD K. SIEGEL and MURRAY E. JARVIK \\ Department of Psychiatry and Biobehavioral Sciences \\ University of California, Los Angeles, California 90024
}

\begin{abstract}
Three rhesus monkeys trained to smoke lettuce cigarettes for water reward extinguished responding when given water ad lib or when the hallucinogen dimethyltryptamine (DMT) was added to the lettuce. Monkeys were then individually confined to an operant unit placed in a sensory isolation chamber that deprived them of light and sound but permitted infrared video monitoring. After continuous isolation for several days, two monkeys consistently selfadministered DMT in performance marked by dramatic changes in perceptual-motor behaviors. These results suggest that animals will self-administer a hallucinogen when it provides stimulation in an otherwise deprived environment.
\end{abstract}

It is a traditional biological assumption that plants produce hallucinogenic compounds as defensive mechanisms to deter herbivores (Rosenthal \& Janzen, 1979). Most hallucinogens taste bitter, produce numbing sensations, and cause a wide range of physiological and psychological activity, resulting in unpleasant and aversive experiences. These include dizziness, nausea, vomiting, perceptual distortions, ataxia, inappropriate and bizarre behavior, hallucinations, and, in sufficient dosages, death. The inevitable ecological encounters between animals and these naturally occurring plant drugs give rise to numerous intoxications and poisonings (Siegel, 1973). But most animals use acute sensory mechanisms to detect the bitter compounds, learn from feeding mistakes, and develop feeding strategies to minimize intake of plant drugs and maximize nutrition. While there is some accidental browsing or forced feeding of plant drugs when other preferred forage is unavailable, most herbivores will not self-administer plant hallucinogens in natural habitats (see review by Siegel, 1979).

Therefore, it is not surprising that animals in laboratory environments do not readily self-administer these hallucinogenic drugs (Griffiths, Brady, \& Bradford, 1979). Most hallucinogens act as effective aversive stimuli, and they can be used to produce conditioned taste aversions in several species such as rats and squirrel monkeys. In rhesus monkeys, most drugs of human abuse will serve as reinforcing stimuli in self-administration studies. However, these animals generally refuse experimental efforts to produce self-administration of hallucinogens. There are some partial successes. Pickens, Thompson, and Muchow (1973) reported that two monkeys self-administered burning hashish via smoking

This research was supported in part by USPHS Grant MH23880. It is based on a paper presented at the Twentieth Annual Meeting of the Psychonomic Society, November 8-10, 1979, Phoenix, Arizona. The authors thank Charles Scott for technical assistance. Reprints may be obtained from R. K. Siegel, P.O. Box 84358, VA Branch, Los Angeles, California 90073. on an FR 10 schedule, but only after prior exposure to the drug (which traditionally attenuates aversive effects) and only when food was concurrently available. Making food available ad lib resulted in extinction of hashish smoking. The arylcycohexylamines, a unique class of drugs with hallucinogenic properties, are consistently self-administered by rhesus monkeys (Balster, Johanson, Harris, \& Schuster, 1973; Moreton, Melsch, Stark, \& Thompson, 1977; Pickens et al., 1973). But these compounds, which include phencyclidine (PCP) and ketamine, have mixed actions, including stimulant, sedative, and anesthetic effects, and the specific stimulus properties involved in their self-administration are unclear (see Mello, 1978). Similarly, the phenylethylamine MDA is self-administered by baboons (Griffiths, Winger, Brady, \& Snell, 1976), but its reinforcing effects are probably unrelated to hallucinogenic action (Griffiths et al., 1979).

In humans, hallucinogens can also produce aversive consequences, ranging from mild dizziness to anxiety and panic. Environments characterized by intense external stimuli seem to promote panic reactions, and "bad trips" often ensue. Consequently, sophisticated users seek out quiet and dark environments in which to experience the excitatory and rewarding drug effects. In such dark settings, users report attenuation of unpleasant reactions, concomitant with a heightening of entertaining visual imagery. Repeated use of hallucinogens is generally motivated by a desire to experience these novel sensory states, which are interpreted as stimulating and rewarding.

Isolated and deprived monkeys also appear to find external stimuli exciting and rewarding. In a series of classic studies, Butler $(1953,1957,1958)$ demonstrated that monkeys confined to an opaque box would learn a discrimination in order to earn a peek through a window at the laboratory environment in which the box was situated. Learning occurred quickly, and the response was quite persistent.

In view of these considerations, a logical question can 
be asked: If isolated monkeys will work to earn access to a window in their box, what would happen if the only window available was a hallucinogenic drug window? The evidence in the existing literature suggests that monkeys might self-administer a hallucinogen under such conditions. Parker (1966) had already demonstrated. that darkness is an aversive stimulus condition for monkeys and that light functions as an effective positive reinforcer. It is possible that the visual stimulation from drug-induced hallucinations might provide a reinforcement for monkeys placed in an aversive condition of darkness. Indeed, there is electrophysiological data suggesting that hallucinogens like LSD and DMT "mimic" the effect of light on the retina (Heiss, Hoyer, \& Poustka, 1973) or on EEG tracings (Marczynski, 1972). Such drugs "might be interpreted by the brain as light and this may contribute to the origin of abnormal reactions within brain structures which are also influenced, leading to hallucinations" (Heiss, et al., 1973, p. 457).

Previous studies have demonstrated that dimethyltryptamine (DMT) is a short-acting (30 $\mathrm{min})$ hallucinogen that changes the frequency of certain behaviors in rhesus monkeys (Siegel, Brewster, \& Jarvik, 1974). When the drug is given in well-illuminated laboratory environments, monkeys show a decrease in exploratory behavior and appear preoccuppied with internally generated stimuli. In completely dark environments, DMT causes an increase in exploratory behavior (Brewster, Siegel, Johnson, \& Jarvik, 1976). In addition, behaviors such as tracking (coordinated hand-eye movements) and fear grimaces, usually associated with specific stimuli, emerged in the absence of such stimuli in the dark when monkeys were given DMT. These results suggested that DMT induced changes in perceptualmotor systems, if not hallucinations per se. In addition, DMT is ideally suited to self-administration studies, since it is short-acting and tolerance does not occur. It is also effective via smoking, a response that monkeys can readily acquire when working for other drugs, such as cocaine (Siegel \& Jarvik, 1980; Siegel, Johnson, Brewster, \& Jarvik, 1976). Thus, the present study was designed to investigate the self-administration of DMT via smoking in isolated monkeys.

\section{METHOD}

\section{Subjects}

Three adult rhesus monkeys (approximately 15 years old and $7.6 \mathrm{~kg}$ ) were used as subjects. The monkeys had been used in previous smoking studies with tobacco and cocaine. They had no prior experience with hallucinogens and were drug free for 2 months prior to the start of this experiment.

\section{Preparation of DMT Cigarettes}

Previous studies had determined that $2 \mathrm{mg} / \mathrm{kg}$ of DMT administered intramuscularly resulted in behavior characterized by increased visual exploration in a dark chamber without accompanying fear grimaces or other associated "aversive" reactions. Since it is estimated that only $30 \%$ of DMT available in the burning cigarette is delivered to the mainstream of inhaled smoke, a total of $50 \mathrm{mg}$ of DMT was provided in each cigarette in order to deliver $2 \mathrm{mg} / \mathrm{kg}$. The cigarettes were unfiltered commercial lettuce cigarettes (Lactuca sativa: Bravo Smokes, Inc., Hereford, Texas). They were individually injected with $50 \mathrm{mg}$ of DMT in a dilute acetic acid solution and allowed to dry.

\section{General Procedure}

The monkeys were trained to puff on lettuce cigarettes according to a previously described procedure (Jarvik, 1967). Briefly, the apparatus consisted of a large operant unit equipped with a stainless steel smoking tube adjacent to a solenoidoperated water-delivery spout. The tube extended $5 \mathrm{~cm}$ from the wall of the unit, allowing the monkey to easily grasp it. The ends of the smoking tube were flattened so that licking behavior and other components of the drinking response were prevented and the animal was required to suck or inhale smoke rather than lick smoke. Monkeys were trained to puff on the smoking tube in order to gain access to a $1.5-\mathrm{ml}$ water reward. Puff duration was gradually shaped to $1 \mathrm{sec}$, and monkeys earned all their water in this manner in daily 1 -h sessions. Companion studies using radioactively labeled smoke indicated that some smoke was inhaled into the lungs via this procedure (Robinson, Siegel, \& Johnson, 1974).

Initially, lettuce cigarettes were available on a dispenser connected to the smoking tube. The dispenser positioned a cigarette behind the tube, and the animal's first puffing response ignited it. As the cigarette burned to within $10 \mathrm{~mm}$ of the end, a thermistor circuit rotated the dispenser, bringing a new cigarette into position and lighting it. A total of 30 cigarettes could be delivered to the animal in this way. Vacuum switches sensed puff duration, and programming equipment located in an adjacent room recorded number of cigarettes, puffs, individual puff durations, and rewards.

\section{Isolation Chamber}

For sessions involving sensory isolation, the operant smoking unit was installed in an observation cage equipped with a clear Plexiglas door. The cage was illuminated from above by two 40-W (constant-voltage) bulbs, covered with infrared filters. A Sony AV-3210 television camera, modified for infrared sensitivity and equipped with an $8.5-\mathrm{mm}$ lens, was placed approximately $1 \mathrm{~m}$ in front of the Plexiglas door. The cage and camera were enclosed in a sound- and light-attenuated chamber (Industrial Acoustics Company, Model 1202-A) equipped with ventilation fans and exhaust. The camera was connected to a video monitor and cassette recorder located outside the chamber. Programming equipment for the operant smoking unit and its cigarette dispenser were also located outside the chamber. Observers, also located outside the chamber, scored behavior in terms of the frequency of 18 behavioral categories: locomotion, exploration (also duration), inappropriate (also duration), stereotypy, yawn, vocalization, spasm, rocking, groom, selfclasp, self-bite, fear grimace, threat, tracking, grope, and bump (see Siegel et al., 1974, for description of categories).

\section{Treatments}

The experiment was conducted in six treatment blocks. The first block (lettuce and water) consisted of 10 successive daily 1-h sessions during which lettuce cigarettes were available. Animals were water deprived and earned all of their daily water in these 1-h sessions (with subsequent supplements in home cages if necessary). The second block (lettuce) consisted of 10 successive daily sessions during which lettuce cigarettes were available and animals received water ad lib in their home cages prior to each session. In these sessions, the water-delivery system was still operated so as to minimize disruption of stimulus control. In the third block (lettuce, isolation), animals were placed individually in the isolation chamber, in total darkness, and were 
allowed to live there, $24 \mathrm{~h} /$ day, for 10 consecutive days, with unlimited access to food and water. Cages were dimly illuminated for approximately $5 \mathrm{~min}$ each day for cleaning, feeding, and changing of the cigarette dispenser. Lettuce cigarettes were continually available during these sessions. The dispenser was automatically rotated once per hour, allowing access to only one cigarette per hour. A slight modification to the programming equipment allowed for the animal's first puff on the smoking tube to ignite each new cigarette.

The fourth block (DMT and water) consisted of 10 successive daily 1-h sessions during which DMT cigarettes were available and animals were water deprived and earned all of their daily water during these sessions. The fifth block (DMT) consisted of 10 successive daily sessions of $1 \mathrm{~h}$ each during which DMT cigarettes were available and water was given ad lib in the home cages prior to each session. In the sixth block (DMT, isolation), animals were once again placed in the sensory-isolation chamber for $24 \mathrm{~h} /$ day with freely available food and water. DMT cigarettes were available once per hour. Initially run for 10 consecutive days, Block 6 was eventually extended to 20 consecutive sessions. The six blocks were conducted over a period of 6 months, with regular (lettuce and water) training sessions run between blocks.

\section{RESULTS}

The results are presented in Table 1 in terms of the means of smoking measures for each block of treatment sessions for each monkey. Here, it can be seen that all monkeys showed substantial smoking of lettuce cigarettes when working for water reward (Block 1), but such smoking behavior was virtually extinguished when water was available ad lib (Block 2) and when monkeys were confined to the isolation chamber (Block 3). All three monkeys showed a minimal amount of DMT smoking when working for water reward (Block 4), but most of this smoking occurred during the early sessions of this block. It appeared that this initial exposure to DMT was aversive, as all monkeys hesitated to approach the smoking tube during the remaining sessions in this block

Table 1

Means of Smoking Measures for Each Block of Treatment Sessions for Each Monkey

Block 1 Block 2 Block 3 Block 4 Block 5 Block 6

\begin{tabular}{rrrrrrr}
\hline \multicolumn{7}{c}{ Monkey S1 } \\
$\mathrm{C}$ & 4.7 & 4.0 & 1.1 & 1.3 & .0 & 1.7 \\
$\mathrm{P}$ & 142.4 & 27.2 & 8.8 & 3.8 & .0 & 45.3 \\
$\mathrm{~T}$ & 132.7 & 9.4 & 3.3 & .9 & .0 & 23.2 \\
& \multicolumn{7}{c}{ Monkey S2 } \\
$\mathrm{C}$ & 5.6 & .6 & .2 & .5 & .8 & 1.8 \\
$\mathrm{P}$ & 240.4 & .1 & .0 & .1 & .0 & 47.7 \\
$\mathrm{~T}$ & 202.9 & .3 & .3 & .2 & .2 & 34.2 \\
& \multicolumn{7}{c}{ Monkey S3 } & & & \\
$\mathrm{C}$ & 6.7 & .0 & .0 & .9 & .0 & .2 \\
$\mathrm{P}$ & 353.1 & .0 & .0 & 7.5 & .0 & 5.9 \\
$\mathrm{~T}$ & 373.9 & .0 & .0 & 13.4 & .0 & .2 \\
\hline
\end{tabular}

Note-C $=$ mean number of cigarettes consumed; when multiplied by 50, this number represents the amount (in milligrams) of DMT available in DMT sessions. $P=$ mean number of puffs per session. $T=$ mean total duration of puffing per session (in seconds). See text for explanation of blocks.

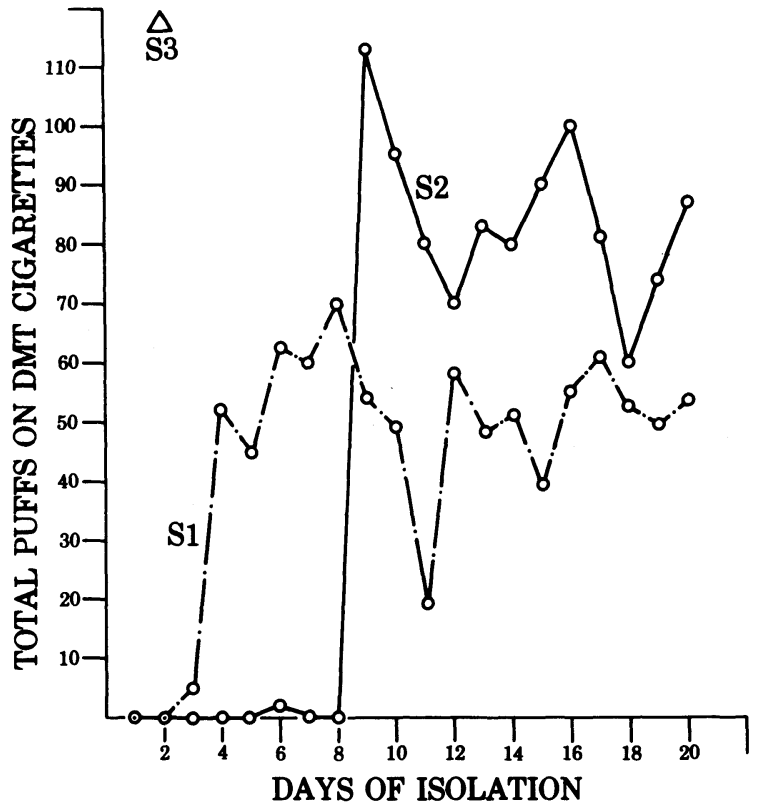

Figure 1. Total puffs on DMT cigarettes for each monkey during days of isolation.

and when water was available ad lib (Block 5). Nonetheless, some puffing on DMT cigarettes continued for Monkey S2 on a daily basis.

Smoking performance during Block 6 sessions, when DMT cigarettes were available in the isolation chamber, was dramatic. Figure 1 shows total puffs on DMT cigarettes for each monkey during isolation sessions. Monkey S1 completely ignored the smoking tube for the first 2 days of isolation and then executed a few puffs on one cigarette on Day 3. Regular smoking of approximately two cigarettes per day began on the 4th day and continued for the rest of the treatment block. Monkey S2 ignored the smoking tube for the first 8 days. On Day 9, this monkey initiated smoking of two cigarettes and continued steady rates of smoking behavior for the remainder of the block. Smoking behavior here was characterized by puff durations and frequencies significantly greater than those emitted in all other blocks except Block 1. Interestingly, once DMT smoking was initiated in isolation, it continued at steady rates throughout the isolation sessions. Daily distribution of DMT puffs during Block 6 indicated that both Monkeys S1 and S2 tended to smoke in clusters of puffs spaced at least $30 \mathrm{~min}$ apart. This distribution coincides with DMT's short duration of action of approximately $30 \mathrm{~min}$. Monkey S3 smoked DMT cigarettes on Day 2 only and did not approach the smoking tube at any other time during the entire isolation period.

Concomitant with the self-administration of DMT cigarettes, observers recorded an increase in behaviors associated with hallucinogenic intoxication. Locomotion increased for all monkeys following DMT; this included crawling movements in one monkey and 
backward falls by another. Exploration also increased, and monkeys tended to spend more time engaged in inappropriate behaviors, including lying prone on the cage floor, circling, and bumping and groping cage walls. Orienting responses and startle reactions appeared periodically for S1 and S2. Tracking movements executed with the eyes and/or hands increased directly as a function of puffs on DMT cigarettes. Monkey S2, following his initial DMT cigarette on Day 9, repeatedly moved his hands over the cage floor, following them with his eyes-movements virtually identical to those observed in the tracking of real objects. These observations confirm that the self-administration of DMT cigarettes here resulted in behaviorally effective dosages.

\section{DISCUSSION}

The most apparent aspect of these findings is that monkeys will self-administer DMT via a smoking response when confined to an isolated environment, but they refuse the drug when placed in normal laboratory environments, even when water reward is contingent on the response. Furthermore, selfadministration of DMT resulted in behaviors characteristic of hallucinogenic intoxication.

Hallucinogens are generally aversive, and DMT, when given to monkeys here in normal laboratory environments with or without contingent water, was aversive. After a few puffs on DMT cigarettes, monkeys frequently exhibited aggressive displays, threats, and barks directed at the smoking tube. However, during isolation sessions, two monkeys self-administered the DMT, and the steady puff rates were robust phenomena for both animals. Aggressive encounters with the smoking tube were rare. It may be speculated that the failure of Monkey S3 to self-administer DMT during isolation resulted from an initial high-dose intoxication on Day 2, which was marked by convulsions and spasms. This may have produced a conditioned aversion to the puffing response, which subsequently extinguished.

The data clearly indicate that two monkeys responded for DMT cigarettes. It could be argued that the light was a reinforcer here, since some light was produced by puffing on a burning cigarette and this faintly illuminated the otherwise totally dark chamber. However, these conditions were also present during lettuce isolation sessions in Block 3 , in which no substantial smoking occurred. A more salient explanation is that stimulation by the visual effects or "internal hallucinatory light" generated by DMT was the effective reinforcer, perhaps coupled with other drug effects as well. More complete tests of DMT's reinforcing properties in isolation sessions would require either challenges with forced injections of DMT or choice trials with cigarettes containing short-acting nonhallucinogenic stimulants. Nonetheless, the drug-taking behavior here was dramatically facilitated by the change in environmental isolation. This finding should help our understanding of the environmental conditions that motivate similar drug self-administration in man. That the aversive consequences of such drug use can be overshadowed by contextual environmental stimuli is not only evident, it is enlightening.

\section{REFERENCES}

Balster, R. L., Johanson, C. E., Harris, R. T., \& Schuster,

C. R. Phencyclidine self-administration in the rhesus monkey.

Pharmacology, Biochemistry and Behavior, 1973, 1, 167-172.

Brewster, J. M., Siegel, R. K., Johnson, C. A., \& Jarvik, M. E. Observational determination of dose-response curves in hallucinogen-treated monkeys. International Pharmacopsychiatry, 1976, 11, 102-108.

Butler, R. A. Discrimination learning by rhesus monkeys to visual-exploration motivation. Journal of Comparative and Physiological Psychology, 1953, 46, 95-98.

Butle R, R. A. Discrimination learning by rhesus monkeys to auditory incentives. Journal of Comparative and Physiological Psychology, 1957, 50, 239-241.

Butler, R. A. The differential effect of visual and auditory incentives on the performance of monkeys. American Journal of Psychology, 1958, 71, 591-593.

Griffiths, R. R., Brady, J. V., \& Bradford, L. D. Predicting the abuse liability of drugs with animal drug self-administration procedures: Psychomotor stimulants and hallucinogens. In T. T. Thompson \& P. B. Dews (Eds.), Advances in behavioral pharmacology (Vol. 2). New York: Academic Press, 1979.

Griffiths, R. R., Winger, G., Brady, J. V., \& Snell, J. D. Comparison of behavior maintained by infusions of eight phenylethylamines in baboons. Psychopharmacologica, 1976, 50, 251-258.

Heiss, W. D., Hoyer, J., \& Poustka, F. Participation of ictural mechanisms in DMT hallucinations. Experientia, 1973, 29, 455-457.

JARVIK, M. E. Tobacco smoking in monkeys. Annals of the New York Academy of Sciences, 1967, 142, 280-294.

MARCZYNSKI, T. J. Lysergic acid diethylamide (LSD-25) mimics the effect of diffuse light on EEG correlates of conditioned operant behavior in cats. Experimental Neurology, 1972, 34, 255-263.

Mello, N. K. Control of drug self-administration: The role of aversive consequences. In R. C. Peterson \& R. C. Stillman (Eds.), Phencyclidine (PCP) abuse: An appraisal (NIDA Research Monograph 21). Washington, D.C: U.S. Government Printing Office, 1978.

Moreton, E. J., Melsch, K. A., Stark, L., \& Thompson, T. Ketamine self-administration by the rhesus monkey. Journal of Pharmacology and Experimental Therapeutics, 1977, 203, 303-309.

PARKER, C. E. Total darkness as an aversive stimulus condition for the squirrel monkey. Psychonomic Science, 1966, 6, 111-112.

Pickens, R., Thompson, T., \& Muchow, D. C. Cannabis and phencyclidine self-administration by animals. In L. Goldberg \& F. Hoffmeister (Eds.), Psychic dependence. New York: Springer-Verlag, 1973.

Robinson, G. D., Siegel, R. K., \& Johnson, C. A. Evaluation of learned "puffing response" of monkeys with In-113 labeled smoke. Journal of Nuclear Medicine, 1974, 15, 528.

Rosenthal, G. A., \& Janzen, D. H. (Eds.). Herbivores. Their interaction with secondary plant metabolites. New York: Academic Press, 1979.

SiEgEL, R. K. An ethologic search for self-administration of hallucinogens. International Journal of the Addictions, 1973, 8, 373-393.

Siegel, R. K. Natural animal addictions: An ethological perspective. In J. D. Keehn (Ed.), Psychopathology in animals. New York: Academic Press, 1979.

Siegel, R. K., Brewster, J. M., \& Jarvik, M. E. An observational study of hallucinogen-induced behavior in unrestrained Macaca mulatta. Psychopharmacologica, 1974, 40, 211-223.

SiEgEL, R. K., \& JARVIK, M. E. Self-regulation of coca-chewing and cocaine-smoking by monkeys. In F. A. Jeri (Ed.), Cocaine 1980. Lima: Pan American Health Organization, 1980.

Siegel, R. K., Johnson, C. A., Brewster, J. M., \& Jarvik, M. E. Cocaine self-administration in monkeys by chewing and smoking. Pharmacology, Biochemistry and Behavior, 1976, 4, 461-467. 